\title{
Validation of the adherence evaluation of osteoporosis treatment (ADEOS) questionnaire for osteoporotic post-menopausal women
}

\author{
V. Breuil • B. Cortet • F.-E. Cotté • B. Arnould • \\ C. Dias-Barbosa - A.-F. Gaudin - A. Regnault • \\ A. Roborel de Climens $\cdot$ E. Legrand
}

Received: 16 April 2010 / Accepted: 19 January 2011 /Published online: 6 April 2011

(C) The Author(s) 2011. This article is published with open access at Springerlink.com

\begin{abstract}
Summary We developed and validated a specific 12-item questionnaire to evaluate adherence to oral antiresorptive medication by post-menopausal osteoporotic women in everyday practice. Over the following 9 months, an index of $\leq 16$ was associated with an increase in the risk of treatment discontinuation of 1.69 and of 2.10 for new patients who had started treatment within the previous year. Introduction Adherence to medication in osteoporosis is poor. The goal of this study was to develop and validate a disease-specific questionnaire to evaluate adherence to treatment of women with post-menopausal osteoporosis taking oral antiresorptive medication.
\end{abstract}

Electronic supplementary material The online version of this article (doi:10.1007/s00198-011-1555-8) contains supplementary material, which is available to authorized users.

\footnotetext{
V. Breuil

Rheumatology Department, Nice University Hospital,

Nice, France

B. Cortet

Rheumatology Department, Lille University Hospital,

Lille, France

F.-E. Cotté $(\bowtie) \cdot$ A.-F. Gaudin

Health Outcomes Studies Department, Laboratoire

GlaxoSmithKline,

Marly le Roi, France

e-mail: francois-emery.e.cotte@gsk.com

B. Arnould $\cdot$ C. Dias-Barbosa $\cdot$ A. Regnault $\cdot$

A. Roborel de Climens

MAPI Values,

Lyon, France

E. Legrand

Rheumatology Department, Angers University Hospital,

Angers, France
}

Methods A prototype adherence questionnaire with 45 items developed from patient interview, literature review, and physician opinion was evaluated in a sample of 350 post-menopausal women with osteoporosis treated in primary care. Item responses were matched against scores on the Morisky Medication Adherence Scale (MMAS). The most discriminant items were retained in the final questionnaire. Concurrent and predictive validity were assessed. Results Twelve items were associated with MMAS score at a probability level of 0.05 . These were retained in the final questionnaire which provided an adherence index ranging from 0 to 22 . An index of $\geq 20$ was associated with a high probability of persistence and an index $\leq 16$ with a high probability of treatment discontinuation in the following 9 months.

Conclusions The ADEOS-12 is a simple patient-reported measure to determine adherence to osteoporosis treatments with good concurrent and discriminant validity. This is the first disease-specific adherence measure to have been developed for osteoporosis.

Keywords Adherence $\cdot$ Compliance $\cdot$ Patient-related outcomes · Persistence · Post-menopausal osteoporosis · Questionnaire

\section{Introduction}

Osteoporosis is a bone disorder characterised by low bone density associated with a deterioration in bone quality (architecture, turnover, damage accumulation, and mineralization) resulting in an increase in bone fragility [1]. This leads to an increase in the risk of fractures, particularly of the hip and vertebrae, which is associated with elevated morbidity and mortality [2-4]. Osteoporosis affects one woman in three after menopause [5] and is recognised by 
the WHO as a major public health problem for prevention, diagnosis, and treatment.

Osteoporosis can be effectively treated by therapies that promote bone consolidation or prevent bone resorption, such as the bisphosphonates [6], selective oestrogen receptor modulators (SERMs) [7], strontium ranelate [8], and teriparatide [9]. In randomised clinical trials, these treatments can reduce fracture incidence by up to $50 \%$. However, in routine care, these treatment benefits may be compromised by poor adherence to treatment, with around $50 \%$ of women discontinuing treatment within 1 year $[10$, 11]. Suboptimal adherence to antiresorptive treatment has been shown to be associated with an increased risk of fracture [12-14]. Barriers to better adherence to osteoporosis treatment include the constraints associated with the administration of some of these agents, side-effects, the treatment regimen, the lack of a visible "read-out" of treatment benefit and inappropriate patient expectations and perceptions [15-17].

Improving adherence to osteoporosis treatment thus represents an important public health issue. Achieving this requires appropriate tools to measure adherence which can be used to monitor improvements due to public health interventions. The notion of adherence involves a number of inter-related aspects. With regard to osteoporosis, an expert consensus recently described adherence as a general term encompassing both compliance and persistence [18]. Compliance was defined as the extent to which a patient acts in accordance with the prescribed interval and dose of a given treatment regimen, whereas persistence was defined as the cumulative time from initiation to discontinuation of therapy.

Currently, three principal types of adherence measure have been developed, prescription follow-up or pharmacy claims to determine medication consumption over time, direct medication use measures (for example, pill counts, electronic measures or canister weights) or patient reports. Direct medication use measures are not particularly useful for naturalistic studies, since they may lead to bias due to potential modification of adherence behaviour by implementation of the reporting measure. Of the prescription follow-up methods, the medication possession ratio (MPR) $[19,20]$ has been widely used. A number of patient-reported measures of treatment adherence have been developed and validated, including the Morisky Medication Adherence Scale (MMAS) [21], the Medication Adherence Report Scale [22], the Adherence to Refills and Medications Scale [23], the ASK-20 [24] and the Hypertension Compliance Questionnaire [25]. However, none of these instruments were designed specifically with osteoporosis in mind, and it would therefore be of interest to develop a disease-specific adherence measure which would focus on adherence issues that are pertinent to osteoporosis and its treatment and may be more discriminating and sensitive to change than non-specific measures.
The primary objective of this study was to develop and validate a disease-specific questionnaire to evaluate adherence to treatment of women with post-menopausal osteoporosis taking oral antiresorptive medication. The secondary objective was to estimate the ability of this questionnaire to predict treatment discontinuation or persistence.

\section{Methods}

The study was performed in France during 2008. The questionnaire was developed in a population of women with post-menopausal osteoporosis consulting a primary care physician and treated for osteoporosis in the previous 6 months. The study includes a cross-sectional phase and a prospective phase. In the cross-sectional phase, data was collected at the study visit, both from a questionnaire provided to the patient and from patient records. In the prospective phase, prescription data were collected over the 9 months following the index consultation.

\section{Ethics}

The survey protocol was submitted for evaluation to the CCTIRS (National Ethics Advisory Board). They considered that participation of patients in the study would not affect their medical care and therefore it was not necessary to obtain formal Ethics Committee approval or to collect signed informed consent from each patient. The only requirement stipulated was that formal information on the goals and methods of the study be provided for each patient. Analyses performed using the Thalès database have been approved by the Commission Nationale de L'informatique et des Libertés (CNIL).

\section{Participating physicians}

The study was performed through the participation of 286 general practitioners (GPs) belonging to the Thalès network. This is a computerised network of 1,200 GPs who contribute exhaustive anonymous data on patient consultations and treatment to a centralised electronic database, allowing subsequent follow-up of outcomes. GPs participating in the Thalès network are selected to be representative of the French GP population according to three main criteria, namely geographical area, age, and gender. Activity and prescription habits of the panel have also been compared a posteriori with national data and shown to be representative [26]. The database currently includes records for $>1.6$ million patients, routinely collected since 2002 . The Thalès database has been demonstrated to be a reliable source of information in numerous previous studies in rheumatology [26-28] and in other fields of medicine [29-32].

For each patient, information on disease status and medication prescription is entered directly into the database 
by the physician at the time of the consultation. No information as to the reasons for making individual diagnostic or prescription choices is however provided. The disease status is encoded using terms from a specific thesaurus of symptoms and disease entities adapted from the International Classification of Diseases (ICD-10) system. Prescription data contain the dispensed drug name (commercial and international common denomination), the Anatomical Therapeutic Chemical (ATC) classification category, dose regimens and prescription duration.

\section{Patients}

Women aged 50 years or older were eligible for the study if they had been prescribed a specific oral osteoporosis treatment (namely, bisphosphonates, SERMs or strontium ranelate) within the 6 months preceding the start of the study. Patients were required to have sufficient cognitive and linguistic abilities, in the opinion of their GP, to complete the study questionnaires on their own, and to provide informed consent. Women participating in clinical trials and those receiving an injectable osteoporosis treatment (intravenous bisphosphonates and teriparatide) were excluded, as well as patients with severe or progressive diseases for whom the physician considered participation inappropriate.

\section{Data collection}

Two types of data were collected during the study. Crosssectional data were collected at the time of the study and retrospective data were derived from the Thalès data. At the time of the study visit, the patients were handed an ADEOS questionnaire and an MMAS questionnaire to be completed on their own and returned to the study centre. Physicians completed an on-line Web-based case report form collecting data on patient demographics, clinical history and current treatment (medication type, dose, frequency of administration). The physicians also rated whether they considered each patient to be adherent to treatment or not, using a six-point Likert scale (all of the time, most of the time, from time to time, rarely, never or no idea). Retrospective data retrieved from the Thalès database provided information on treatment history and were used to calculate the MPR. Information was also collected on the age, gender and size of practice of participating GPs to allow comparison with national norms.

\section{Development of the ADEOS questionnaire}

The ADEOS (ADherence Evaluation of OSteoporosis treatment) questionnaire was developed to determine adhesion to osteoporosis treatments. A Scientific Expert Committee was involved with the development of the questionnaire and was consulted between each stage of the development process to ensure the credibility and pertinence of the proposed next steps. The development of the questionnaire followed the following steps.

The first step was an exploratory phase aimed at identifying themes potentially important to include in the questionnaire. A review of the scientific literature allowed existing instruments for the evaluation of adherence or persistence with osteoporosis treatment to be identified, as well as other relevant concepts that may be interesting to include in the questionnaire. In parallel, a series of face-to-face semi-directive interviews were conducted by an experienced clinical psychologist with ten patients with post-menopausal osteoporosis and experience of treatment, who were proposed by two GPs and a rheumatologist. The aim of these interviews was to collect information on these patients' experience of their osteoporosis and its treatment, to identify barriers and benefits associated with the use of these treatments, and to capture the language used to describe these perceptions.

In a second step, the information collected from the literature review and the patient interviews was used to generate items for a draft questionnaire. This draft questionnaire was tested for comprehension by a panel of five patients currently treated for post-menopausal osteoporosis. The goal of this step was to verify that the selected items were considered understandable and pertinent by the patients and, if this was not the case, to gather suggestions from the patients on how these items could be reformulated (Table 1).

In a third step, a pilot study was implemented with 11 GPs who each recruited three patients treated for osteoporosis. The aim of this pilot study was to evaluate the acceptability of the questionnaire by its target population (patients with osteoporosis) and by potential users (GPs) in terms of relevance, ease of use, applicability and usefulness for assessing adherence [33].

The prototype version of the questionnaire retained after the pilot study was composed of 45 items relating to four general concepts, namely beliefs, perceptions, behaviours and information, as well as general patient data such as age and time since diagnosis (see Table 2). Each item was scored either by a dichotomous Yes/No response or on a three-point Likert scale.

\section{Other adherence measures}

The study also assessed medication adherence using two other non-specific adherence measures that had been validated previously, the MPR [20] and the MMAS [21]. The MPR is defined as the ratio between the length of time for which a patient is in possession of prescribed medication and the time since the first prescription. The MPR was determined from data on all medication prescribed since 2002 (first availability of the Thalès database). Since patients whose treatment was initiated within the 3 months preceding the study visit would 
Table 1 Characteristics of the ADEOS population

\begin{tabular}{|c|c|}
\hline & $N=350$ \\
\hline Age (years) & $70.9 \pm 8.8$ \\
\hline$<65$ years & $98(28.0 \%)$ \\
\hline $65-75$ years & $118(33.7 \%)$ \\
\hline$>75$ years & $134(38.3 \%)$ \\
\hline \multicolumn{2}{|l|}{ Marital status } \\
\hline Living alone & $141(40.3 \%)$ \\
\hline Living with spouse or family & $205(58.6 \%)$ \\
\hline Other & $4(1.1 \%)$ \\
\hline \multicolumn{2}{|l|}{ Educational level } \\
\hline Primary school & $70(20.0 \%)$ \\
\hline College & $152(43.4 \%)$ \\
\hline High school & $70(20.0 \%)$ \\
\hline University & $58(16.6 \%)$ \\
\hline \multicolumn{2}{|l|}{ Employment status } \\
\hline In work & $39(11.1 \%)$ \\
\hline Retired & $301(86.0 \%)$ \\
\hline Out of work & $10(2.9 \%)$ \\
\hline BMI $\left(\mathrm{kg} / \mathrm{m}^{2}\right)$ & $25.0 \pm 5.6$ \\
\hline Previous fracture history & $112(32.0 \%)$ \\
\hline Time since diagnosis (years) & $5.3 \pm 4.7$ \\
\hline Bone densitometry examination & $310(88.6 \%)$ \\
\hline \multicolumn{2}{|l|}{ Treatment } \\
\hline Bisphosphonate & $258(73.7 \%)$ \\
\hline SERM & $58(16.6 \%)$ \\
\hline Strontium ranelate & $34(9.7 \%)$ \\
\hline Daily & $106(30.0 \%)$ \\
\hline Weekly & $179(51.1 \%)$ \\
\hline Monthly & $65(18.6 \%)$ \\
\hline \multicolumn{2}{|l|}{ MPR for all treatments } \\
\hline Mean \pm SD & $82.9 \% \pm 18.7 \%$ \\
\hline Adherent patient (MPR $>80 \%$ ) & $220(62.9 \%)$ \\
\hline Adherent patient (MPR >68\%) & $270(77.1 \%)$ \\
\hline \multicolumn{2}{|c|}{ Physician judgement about patient adherence } \\
\hline All of the time & $273(78.0 \%)$ \\
\hline Most of the time & $67(19.1 \%)$ \\
\hline From time to time & $8(2.3 \%)$ \\
\hline Rarely & $1(0.3 \%)$ \\
\hline Never & - \\
\hline No idea & $1(0.3 \%)$ \\
\hline
\end{tabular}

Quantitative variables are presented as mean values \pm standard deviations and categorical variables as absolute patient numbers (\%)

ADEOS adherence and osteoporosis questionnaire, BMI body mass index, $M P R$ medication possession ratio, $S D$ standard deviation, $S E R M$ selective oestrogen receptor modulator

have an MPR of $100 \%$ de facto (3 months is usually the duration of a single prescription fill in France), these patients were excluded from the analysis. Consistent with previous studies of the MPR in patients with osteoporosis [10, 15, 34], we considered patients with an MPR above 0.80 to be adherent. In addition, a cut-off of 0.68 was also considered, since this threshold has been demonstrated to be the most sensitive for predicting elevated fracture risk in poorly compliant patients [35].

The MMAS [21] is a self-administered rating scale that contains four items relating to medication use behaviour. Each item can be scored 'yes' or 'no', negative replies being attributed a value of 1 and affirmative replies a value of 0 . A high score is associated with good adherence and a score of less than 4 is considered to indicate inadequate adherence. This scale was initially developed with eight items for evaluating adherence to antihypertensive medication, but the four-item short form used in our study is now a generic scale that has been applied to many types of medication.

In addition, we also collected information on the physician's appreciation of their patient's adherence. They were asked whether they thought that their patient was adherent all of the time, most of the time, from time to time, rarely or never, or whether they had no idea. The purpose of this question was to investigate how well the physician could judge their patient's adherence without the use of a specific tool.

Finalisation of the ADEOS questionnaire and definition of an adherence index

For this purpose, the ADEOS study population was divided randomly into two independent data sets. The first set (modelling set) was used to generate the structure of the ADEOS score distribution and the second (validation set) to valid this structure independently. The first 200 randomly selected patients were assigned to the modelling set and the remaining 148 to the validation set. In a first step, the modelling set was used to select those items whose scores were most closely correlated with an independent measure of adherence, the MMAS score. All items associated with the MMAS score were retained in the final questionnaire.

From the items retained, an adherence index was derived by adding the scores of the individual items, having standardised the direction of the response modality so that the highest individual item score always corresponded to the greatest adherence. The score was then tested in the validation set by describing its ability to discriminate between adherent and non-adherent patients assigned by the MMAS score (MMAS score $=4$ and MMAS score $<4$, respectively). Finally, relationships were evaluated between the score and the MPR and between the score and the physician's judgement of patient adherence in the total ADEOS study population.

Prediction of treatment discontinuation

Patient persistence was assessed 9 months after ADEOS completion using prescriptions made to the patients. On 
Table 2 Concepts and items retained in the ADEOS-12 score

\begin{tabular}{|c|c|c|}
\hline General concepts & Content & Items retained in the ADEOS- 12 score \\
\hline Beliefs (12 source items) & $\begin{array}{l}\text { Osteoporosis consequences; osteoporosis acceptance; } \\
\text { about osteoporosis treatment (curative, preventive, } \\
\text { important for health, important compared with } \\
\text { other treatments); instructions to follow: important, } \\
\text { easy; feeling reassured and protected by the } \\
\text { treatment; importance of the BMD test }\end{array}$ & $\begin{array}{l}\text { Item } 29 \text {, "My osteoporosis medication is } \\
\text { important to my health." } \\
\text { Item } 24 \text {, What motivates you to take your } \\
\text { osteoporosis medication? } \\
\text { Item } 25 \text {, How motivated are you to keep } \\
\text { taking your osteoporosis medication? }\end{array}$ \\
\hline Perceptions (ten source items) & $\begin{array}{l}\text { Level of bone fragility; inability to notice osteoporosis } \\
\text { evolution; concern about osteoporosis diagnosis; } \\
\text { concerns (falls, fractures, disability); treatment } \\
\text { constraints; easy to take treatment; treatment efficacy; } \\
\text { inability to notice treatment beneficial effects; } \\
\text { treatment side-effects }\end{array}$ & $\begin{array}{l}\text { Item 16, Do you feel that your osteoporosis } \\
\text { medication is easy to take? } \\
\text { Item } 18 \text {, Are the instructions for taking your } \\
\text { osteoporosis medication inconvenient for you? }\end{array}$ \\
\hline Behaviour (13 source items) & $\begin{array}{l}\text { Forgetting/skipping treatment; tricks for remembering } \\
\text { treatment; involvement of patient (for BMD test, } \\
\text { in decision-making, consulting regularly, seeking } \\
\text { information); daily life adaptation to osteoporosis; } \\
\text { daily life adaptation to treatment; motivations to } \\
\text { take treatment; intention to continue treatment }\end{array}$ & $\begin{array}{l}\text { Item } 21 \text {, Do you ever forget to take your } \\
\text { osteoporosis medication? } \\
\text { Item } 22 \text {, Do you ever skip your medication } \\
\text { because of unexpected circumstances? } \\
\text { Item } 23 \text {, How do you remind yourself to } \\
\text { take your osteoporosis medication? } \\
\text { Item } 30 \text {, "I have become used to taking my } \\
\text { osteoporosis medication." } \\
\text { Item } 31 \text {, "I make sure to carefully follow the } \\
\text { instructions I'm given about taking my } \\
\text { osteoporosis medication." }\end{array}$ \\
\hline Information (three source items) & $\begin{array}{l}\text { Need more information/explanation about osteoporosis } \\
\text { or treatment; information from friends or relations; } \\
\text { consistency of information }\end{array}$ & $\begin{array}{l}\text { Item } 17 \text {, Did you receive specific instructions } \\
\text { on how to take your osteoporosis medication? } \\
\text { Item } 32 \text {, "The instructions for taking my } \\
\text { osteoporosis medication are clear enough." }\end{array}$ \\
\hline Patient features (seven source items) & $\begin{array}{l}\text { Age; diagnosis of osteoporosis; family history of } \\
\text { osteoporosis; fracture history; history of BMD } \\
\text { testing; treatment; reimbursement }\end{array}$ & None retained \\
\hline
\end{tabular}

The wordings of the French and English version of the questionnaire, as well as the scoring system are provided in Appendix 1. ADEOS-12: 12item adherence and osteoporosis questionnaire

$B M D$ bone mass densitometry

the basis of treatment persistence during this 9-month period, patients were divided into a "discontinued" group and a "persistent" group. The ability of the ADEOS index to predict discontinuation was evaluated by calculating the relative risks of treatment discontinuation of patients by ADEOS category. The analysis was replicated in the subgroup of patients with recent treatment initiation $(<1$ year). Other potential predictors of discontinuation were also investigated using univariate logistic regressions: age, professional status, level of education, fracture history, polymedication, length of diagnosis, and treatment duration (more than 6 months vs. less than 6 months).

\section{Statistical analysis}

Two study populations were considered in the analysis, a total study population, and an ADEOS study population. The total study population corresponded to all patients included in the study. The ADEOS study population was arbitrarily defined as all patients who had returned an exploitable ADEOS questionnaire with at least 23 (i.e. half) of the 45 items completed. Missing data were not replaced, and these were taken into account for the calculation of percentages.

Categorical variables were compared with the $\chi^{2}$ test or Fisher's exact test, as appropriate. Quantitative variables were compared using Student's $t$ test or analysis of variance (ANOVA) if these were normally distributed, otherwise with the Mann-Whitney-Wilcoxon test or the Kruskall-Wallis test as appropriate. In order to generate the final questionnaire, all items in the 45 -item questionnaire were tested for their association with adherence measured with the MMAS score. Those items showing a significant association at a probability value of 0.05 (Mann-Whitney $U$ test for dichotomous variables and Kruskall-Wallis test for Likert scales) were retained in the final questionnaire. The performance of the adherence index to discriminate between two patient groups was tested in the validation set using Receiver-Operating Characteristic (ROC) curves.

Data were controlled, validated and analysed centrally. The analyses were performed using SAS ${ }^{\circledR}$ software version 9.1.3 for Windows (SAS Institute, Cary, NC, USA). 


\section{Results}

Study sample

A total of 560 patients were included in the study by 228 GPs. For these patients, Web-based case report forms were completed on-line and this thus constituted the total study population and the physician population. All patients were provided with ADEOS and MMAS questionnaires to complete and return. ADEOS questionnaires were returned by 350 patients $(62.5 \%)$, and these were exploitable for 348 patients who constituted the ADEOS study population. The ADEOS study population was divided into a modelling set $(N=200)$ and a validation set $(N=148)$.

The completion rate of the questionnaire was acceptable, with 194 patients $(55.7 \%)$ filling in the entire questionnaire and $327(93.4 \%)$ completing at least 42 of the 45 proposed items. The mean number of missing items was $1.2 \pm 3.1$. Two items accounted for completion failure in over $30 \%$ of patients. These items were not retained in the final questionnaire. Only two patients failed to complete more than half of the 45 items of the prototype questionnaire and were considered unexploitable.

\section{Patient characteristics}

The characteristics of patients returning their ADEOS questionnaires are presented in Table 1 . The mean age of the sample was $71.2 \pm 8.9$ years and $34.8 \%$ had previously experienced a fracture. The mean time since diagnosis of osteoporosis was $5.4 \pm 4.7$ years and $87.3 \%$ had undergone bone densitometry. The most commonly prescribed treatments for osteoporosis were bisphosphonates (in $75.7 \%$ of patients) and a little over half were prescribed a treatment to be taken weekly $(52.9 \%)$. No difference between patients returning their ADEOS questionnaires and those who did not return them was observed for any of these variables (data not shown).

\section{Measures of adherence}

Previous adherence to osteoporosis treatment was determined using the MPR for the entire treatment period. Mean
MPR values and the proportion of adherent patients using cut-offs of 0.80 and 0.68 are presented in Table 1 . There was no difference in MPR values between the patients returning their ADEOS questionnaires and those not returning them for any of the MPR variables studies, with the exception of the proportion of patients adherent over their entire treatment period using a threshold of 0.80 , which was higher in patients returning their questionnaire $(p=0.021)$.

According to the judgement of the GP as to whether their patients were adherent to treatment or not, $97.1 \%$ of patients were considered to be adherent all or most of the time (Table 1), again with no significant difference between patients returning or not returning their questionnaires (data not shown). For patients returning an MMAS questionnaire, the mean MMAS score was $3.5 \pm 0.8$. The distribution of MMAS score is presented in Fig. 1, with $62.9 \%$ of respondents scoring 4 on this rating scale and thus being considered as adherent.

Adherence measured by the MMAS was significantly associated with the physician's judgement of patient adherence $(p=0.0001)$. However, the correlation between the MMAS and the MPR for the most recent treatment was limited $\left(r^{2}=0.1195 ; p=0.034\right)$, and there was no association between MPR and the physicians judgement $(p=0.749)$.

Item selection and scoring

Overall, 12 items were associated with the MMAS score at a probability threshold of $\leq 0.05$. These are listed in Table 2 . With the exception of Item 23 (19 patients did not reply to this question), data were missing for less than $5 \%$ of patients for the selected items (one to ten patients according to the item).

The scoring system is described in the questionnaire provided in Appendix 1. Three types of question were retained in the questionnaire (Table 3 ). The first type of question (for example, Q9 in Table 3) related to factors that were associated with high MMAS scores and were scored on a three-point Likert scale, with +2 being attributed to the most favourable response, +1 to the intermediate response and 0 to the least favourable response. In a similar fashion, the second type of question related to factors associated
Fig. 1 Distribution of MMAS (left) and ADEOS-12 (right) scores. Data are presented as absolute numbers of patients. ADEOS-12: 12-item adherence and osteoporosis questionnaire; MMAS Morisky Medication Adherence Scale
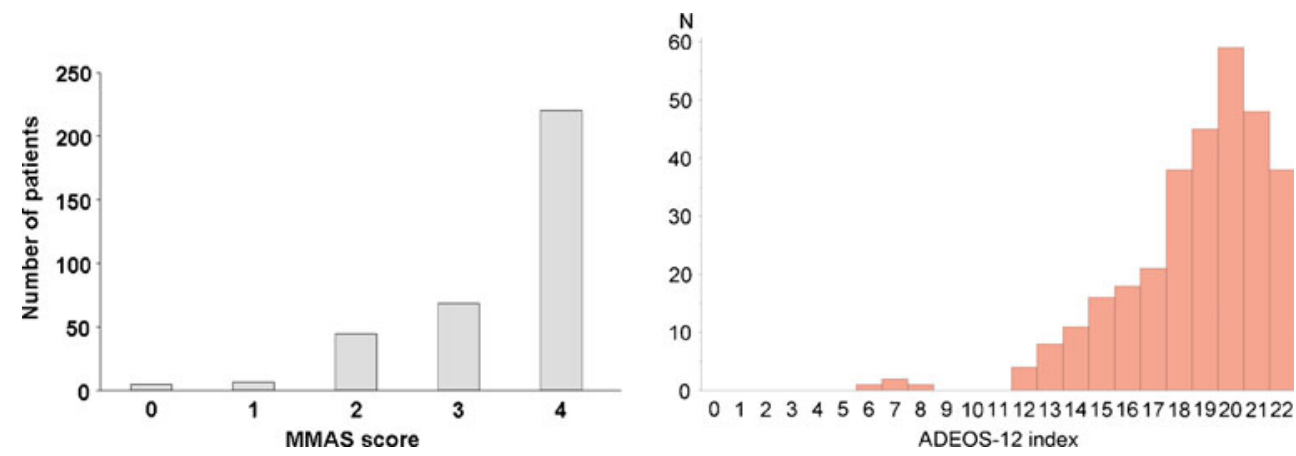
Table 3 Examples of questions and response modalities in the ADEOS-12 questionnaire

Q9. My osteoporosis medication is important to my health

$\begin{array}{llc}\square & \text { Yes, completely } & +2 \\ \square & \text { Somewhat } & +1 \\ \square & \text { No, not at all } & 0\end{array}$

Q4. Do you ever forget to take your osteoporosis medication?

口 Never 0

口 Sometimes

$\square \quad$ Often $\quad-2$

Q6. How do you remind yourself to take your osteoporosis medication

$\begin{array}{lll}\square & \text { The people around me remind me } & 0 \\ \square & \text { I have a way to remind myself } & 0 \\ \square & \text { It has become natural to me } & +1 \\ \square & \text { Other (specify) } & 0 \\ \square & \text { I don't know what to do to remember } & -1\end{array}$

ADEOS-12: 12-item adherence and osteoporosis questionnaire

$B M D$ bone mass densitometry

Note: For routine practice, item's scores can be replace with stars (positive figures) and circles (negative figures) (cf. Appendix 1)

with low MMAS scores (for example Q4), and responses were scored $-2,-1$ or 0 . The third category of question were multiple response questions (for example Q6), in which responses associated with high MMAS scores were attributed +1 and those associated with low MMAS scores -1 . The sum of the scores for each item was calculated and 8 added to this sum in order to avoid potential negative values. This number represented the final ADEOS-12 score, which could take values ranging from 0 (lowest adherence) to 22 (highest adherence).

The distribution of the ADEOS-12 score in the ADEOS study population is illustrated in Fig. 1. The mean $\pm \mathrm{SD}$ and median value of the score were $18.7 \pm 2.8$ and 19 , respectively. The vast majority of patients (percent) presented a score in the upper half of possible scores $(>11)$. No differences in mean ADEOS-12 score or in its distribution, as a function of age group, marital status, educational status, type or frequency of administration of osteoporosis treatment, duration of treatment or use of other medication (data not shown). However, the score was slightly, but significantly $(p=0.048)$ higher in patients without a history of fracture than in those with such a history.

\section{Psychometric validation of the ADEOS-12}

The psychometric validation of the ADEOS-12 questionnaire was performed in the 148 patients in the validation set. The score was moderately correlated with the MMAS score in this population $\left(r^{2}=0.58 ; p<0.0001\right)$. The ADEOS12 showed high discriminatory power with respect to adherence measured with the MMAS, as demonstrated by an estimated area under the ROC curve of 0.842 (Fig. 2).

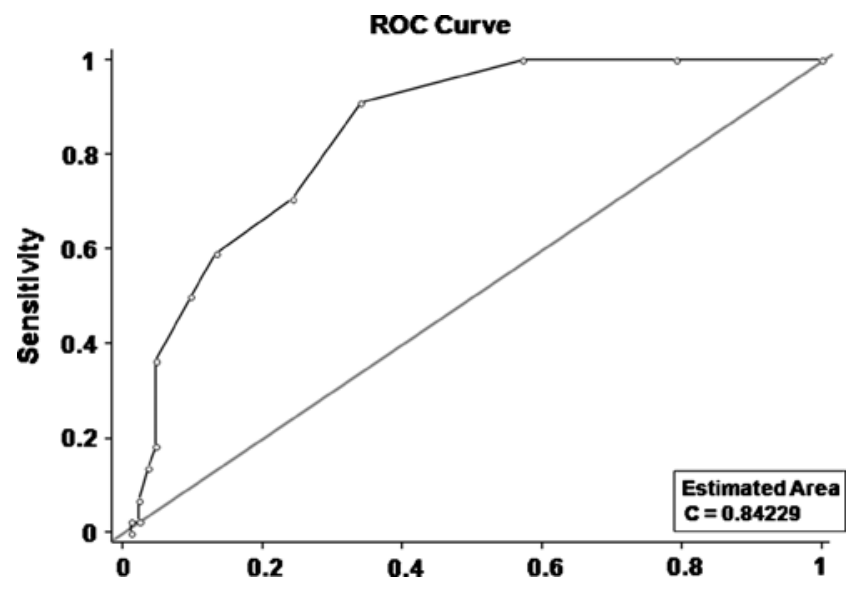

Fig. 2 Receiver-Operating Characteristics curve for the ability of the ADEOS-12 score to discriminate between adherent (MMAS score=4) and non-adherent (MMAS score $<4$ ) defined by the MMAS (Morisky Medication Adherence Scale). ADEOS-12: 12-item adherence and osteoporosis questionnaire

\section{Concurrent validation of the ADEOS-12}

With respect to adherence measured with the MPR, the discriminatory power of the ADEOS-12 was quite low, with estimated areas under the ROC curve ranging from $0.63[95 \%$ confidence limits, 0.52 to 0.76 ] to 0.67 [0.53 to 0.81 ], according to the MPR definition used. The correlation between the ADEOS-12 score and the MPR was low but nonetheless significant (Spearman rank coefficient, $0.12 ; p<0.03$ ). With respect to the physician's judgement, the mean ADEOS-12 score was also significantly higher $(p<0.0001$; Student's $t$ test) in patients who were considered to be adherent all of the time (score $=19.1 \pm 2.4)$ compared with those who were considered not to be always adherent $(17.1 \pm 3.5)$.

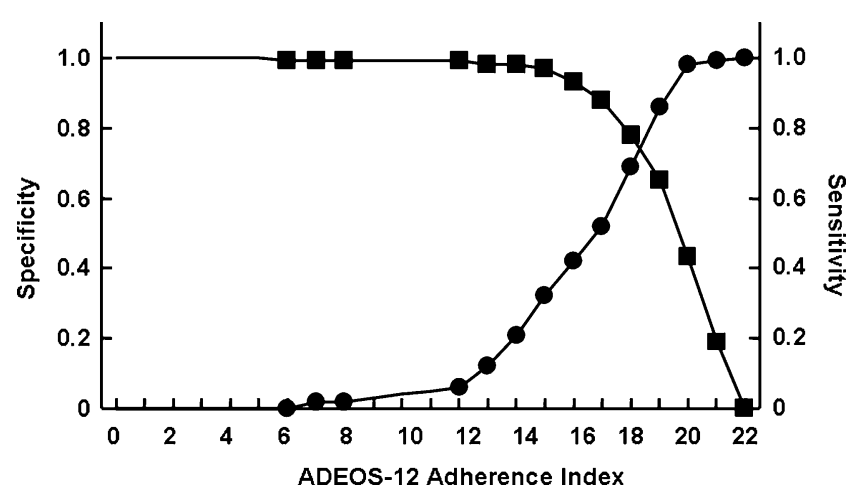

Fig. 3 Sensitivity (closed square) and specificity (closed circle) of the ADEOS-12 Adherence Index at discriminating adherent and non-adherent patients defined with the MMAS (Morisky Medication Adherence Scale). ADEOS-12: 12-item adherence and osteoporosis questionnaire 
Identification of discriminant thresholds for the ADEOS-12 index

The specificity and sensitivity of different score thresholds for detecting patients with an MMAS score of 4 (optimal adherence), and those with a lower score was also evaluated in the total ADEOS population (Fig. 3). Three groups of patients could be distinguished, those with a score $\geq 20$ (the "shoulder" on the specificity curve), those with a score $\leq 16$ (the "shoulder" on the sensitivity curve) and those with a score of 17 to 19 . In the former group, $87.6 \%$ presented an MMAS score of 4 and were thus adherent. For the patients with a score $\leq 16,81.4 \%$ were sub-optimally adherent (MMAS score $<4$ ).

Predictive validity

During the 9 months following the index consultation, all patients returned to consult their GP at least once, irrespective of the reason. Of these, 226 patients $(64.9 \%)$ had been persistent and $122(35.1 \%)$ had discontinued their treatment. The ADEOS score at baseline significantly predicted treatment discontinuation over the following 9-month period ( $p=$ 0.005). Compared with patients with good adherence to treatment (ADEOS score $\geq 20$ ), patients with ADEOS-12 scores between 16 and 19 had a 1.36 times higher risk and those with scores $\leq 16$ a 1.69 times higher risk of treatment discontinuation before 9 months (Table 4). Considering the 119 patients whose treatment had been initiated in the previous year, 68 (57.1\%) were persistent and 51 (42.9\%) had discontinued. In this group, the relative risks of treatment discontinuation were respectively 1.43 and 2.10. No other variable tested was significantly associated with treatment discontinuation at a probability threshold of 0.05 .

\section{Discussion}

This study was performed to develop and validate a diseasespecific, patient-reported measure to evaluate treatment adherence in patients treated chronically for osteoporosis. An extensive 45 -item prototype questionnaire was reduced to a 12-item questionnaire by selection of items most strongly associated with self-reported adherence determined with the MMAS. In an independent validation sample of women treated for osteoporosis, the ADEOS-12 questionnaire showed satisfactory concurrent and discriminant validity. The adherence score also demonstrated a good ability to predict treatment discontinuation over the medium term and particularly in patients with a short treatment history.

The ADEOS-12 score was moderately correlated with the MMAS score $\left(r^{2}=0.58\right)$ and discriminated well between patients considered as optimally adherent (MMAS score $=4$ ) and sub-optimally adherent (MMAS score $<4$ ). Indeed, the area under the ROC curve was 0.842 , demonstrating high specificity and sensitivity. Since the MMAS was used as the criterion to retain items in the ADEOS-12, some correlation is expected as a direct consequence of how the items were selected. However, the correlation may be imperfect, since the ADEOS-12 covers, in addition, attributes of adherence other than those covered by the MMAS. Unlike, the latter, the ADEOS-12 is a specific questionnaire for women treated for osteoporosis and thus may represent a more global measure of adherence in this disease. The proportion of sub-optimally adherent patients determined with the MMAS was $37.1 \%$, which is comparable with the rate of $34.5 \%$, reported recently in a larger survey of post-menopausal women with osteoporosis in France [36].

Furthermore, the ADEOS-12 score also discriminated between patients considered to be always adherent and not always adherent by their physician. In contrast, the ADEOS-12 was poorly, albeit significantly, correlated with the MPR, which reflects the fact that the two instruments do not measure the same thing. Whereas the MPR is an objective measure of expected drug intake (medical prescription/pharmacy retail), the ADEOS score assesses subjective beliefs, perceptions, behaviour and information with regard to treatment. The finding is consistent with many previous studies which have shown that adherence measured by self-report is poorly correlated with measures based on prescription rates or medication use [37-41]. Consistent with this, the relationship between the MPR and the MMAS score in our study was weak, and the MPR was
Table 4 Persistence rates over the 9 months following consultation as a function of ADEOS12 score at the index consultation

Relative risk rates are provided with their 95\% confidence intervals. ADEOS-12: 12-item adherence and osteoporosis questionnaire

\begin{tabular}{lrrl}
\hline & Persistent & Discontinued & Relative risk \\
\hline All patients & & & \\
ADEOS-12 score $\geq 20$ & $103(71.0 \%)$ & $42(29.0 \%)$ & 1 \\
ADEOS-12 score $17-19$ & $74(60.7 \%)$ & $48(39.3 \%)$ & $1.36[0.97-1.90]$ \\
ADEOS-12 score $\leq 16$ & $22(51.2 \%)$ & $21(48.8 \%)$ & $1.69[1.13-2.51]$ \\
Patients starting treatment within previous year & & 1 \\
ADEOS-12 score $\geq 20$ & $30(68.2 \%)$ & $14(31.8 \%)$ & $1.43[0.83-2.45]$ \\
ADEOS-12 score $17-19$ & $24(54.5 \%)$ & $20(45.4 \%)$ & $2.10[1.22-3.60]$ \\
ADEOS-12 score $\leq 16$ & $6(33.3 \%)$ & $12(66.7 \%)$ & \\
\hline
\end{tabular}


not significantly related to the physician's judgement of adherence. Since the ADEOS-12 was developed with benchmarking to the MMAS, it is not surprising that it is correlated with the latter rather than with the MPR. With respect to prospective collection of data on adherence, however, the ADEOS-12 score did perform well in predicting treatment discontinuation, especially in recently treated women who are less likely to be persistent. Physician judgement was of patient adherence seemed overly optimistic, since they considered $97 \%$ of patients to be adherent all or most of the time. As indicated in previous studies, physician judgement of adherence was poorly correlated with patient-reported measures of adherence. This highlights the interest of a simple tool for physicians to use to determine patient adherence, rather than relying uniquely on their own judgement.

The ADEOS-12 presents a number of advantages for the evaluation of treatment adherence in women with osteoporosis. Firstly, it provides a disease-specific measure which captures information on treatment and patient attributes which are pertinent to the disease and which may provide clues to improving adherence. For example, if non-adherent patients consistently report that recommendations for taking their medication are unclear or difficult to follow (items 18 and 32 of the ADEOS), then this would be an incentive to reformulate the recommendations. Although disease-specific adherence questionnaires have been developed in a few disease areas [42-44]; up to now, no such instrument has been made available for the study of osteoporosis. Secondly, the questionnaire is short and simple to use (12 items with either two or three potential response modalities) and seems understandable and acceptable to patients since the amount of missing data on returned questionnaires was limited (only two patients completed less than half the items). The scoring is simple and rapid for the rater to perform. Thirdly, compared with the MMAS, the ADEOS-12 has a richer content, covering multiple aspects of medication use, including perceptions of disease, perceptions of treatment and attitudes to taking medication. Moreover, the score, which ranges over 22 points, offers a more highly resolved estimate of adherence than the four-point MMAS score, whereby different degrees of suboptimal adherence can be identified. In particular, it appeared that the ADEOS-12 index showed a notably less important ceiling effect than the MMAS score, indicating that it may be more able to identify slight deviations from perfect behaviour. Fourthly, the ADEOS-12 score seems to be relatively independent of sociodemographic, clinical and treatment variables, although numerically small, albeit significant, differences were observed for fracture history and treatment duration. This suggests that the ADEOS-12 can provide comparable data from different patient groups and that it is sensitive to psychological variables that may underlie individual differences in adherence, such as treatment expect- ations, disease perceptions, attitudes to risk, mood and patientphysician relationships [45]. Next, the ADEOS-12 provides complementary information to other measures of adherence. It clearly measures a different dimension of adherence to the MPR, with which it is poorly correlated, but also is complementary to the MMAS, providing additional information on patient perceptions, as indicated by the only moderate correlation between the MMAS score and the ADEOS-12 score. In addition, this disease-specific index is complementary to general adherences measures, which are useful to compare adherence across different diseases, but are often relatively insensitive. Finally, psychometric analyses identified two pragmatic score thresholds (16 and 20) which provide a good basis to guide interpretation of the score in daily practice. A patient with an $\mathrm{ADEOS}$ index $\geq 20$ is expected to be unlikely to discontinue while a patient with an index $\geq 16$ is at risk for treatment discontinuation. Given that many of the attributes of medication adherence, for example patient-physician relationships and patient empowerment, are likely to be culturally dependent, it will be important to validate the psychometric properties of the ADEOS-12 questionnaire and its score thresholds in other countries. To this end, a validated translation of the ADEOS12 questionnaire into English is provided in the Appendix.

Our study has certain limitations. Firstly, the response rate was only moderate, with $62.5 \%$ of patients returning a completed ADEOS questionnaire. In order to limit potential social pressure on patients to "conform" [46] and in order to match as closely as possible naturalistic conditions of use of the questionnaire, no attempts were made to contact patients who had not returned their questionnaires spontaneously to remind them to do so. However, even if non-adherent patients are under-represented in our sample, they still make up a significant proportion of the sample, with $26 \%$ having an MPR $<0.80$ for their most recent treatment and 35\% scoring less than four on the MMAS. Another potential source of non-representativity relates to patients who did not return to see their GP after the initial prescription of osteoporosis treatment, who were not accessible for the study. These patients are likely to be non-persistent and the adherence rates estimated in our study may in consequence be somewhat over-estimated. Another limitation is that women receiving injectable antiresorptive treatments were excluded from the study, since it was considered that their adherence behaviour would be governed by quite different principles. The validity and performance of the ADEOS questionnaire in other populations, such as women receiving injectable treatments, remain to be confirmed.

In conclusion, the ADEOS- 12 provides the physician with a simple patient-reported measure to determine adherence to osteoporosis treatments. This is the first disease-specific adherence measure to have been developed for osteoporosis, a disease in which poor treatment adherence is a major issue. 
The questionnaire has good concurrent and discriminant validity; its items are relevant and meaningful to the target population and may provide useful information on why adherence is suboptimal. Its use may provide complementary or more exhaustive information on adherence than currently available non-specific adherence measures.

Funding This study was funded by Laboratoire GlaxoSmithKline and Laboratoire Roche, purveyors of ibandronate, an osteoporosis treatment.

Conflicts of interest Operational management of the study and data analysis was subcontracted to Mapi Values, an independent company specialised in health outcomes research. FEC and AFG are employees of Laboratoire GlaxoSmithKline. AR, CDB, ARC and BA are employees of Mapi Values. VB, BC and ER received consultancy fees and honoraria from Laboratoire GlaxoSmithKline for their contribution to this project.

Open Access This article is distributed under the terms of the Creative Commons Attribution Noncommercial License which permits any noncommercial use, distribution, and reproduction in any medium, provided the original author(s) and source are credited.

\section{References}

1. National Institute of Health (2001) Osteoporosis prevention, diagnosis, and therapy. JAMA 285:785-795

2. Kanis JA, Oden A, Johnell O, De Laet C, Jonsson B (2004) Excess mortality after hospitalisation for vertebral fracture. Osteoporos Int 15:108-112

3. Melton LJ 3rd (2000) Excess mortality following vertebral fracture. J Am Geriatr Soc 48:338-339

4. Melton LJ 3rd, Thamer M, Ray NF, Chan JK, Chesnut CH 3rd, Einhorn TA, Johnston CC, Raisz LG, Silverman SL, Siris ES (1997) Fractures attributable to osteoporosis: report from the National Osteoporosis Foundation. J Bone Miner Res 12:16-23

5. Kanis JA, Gluer CC (2000) An update on the diagnosis and assessment of osteoporosis with densitometry. Committee of Scientific Advisors, International Osteoporosis Foundation. Osteoporos Int 11:192-202

6. Delmas PD (2005) The use of bisphosphonates in the treatment of osteoporosis. Curr Opin Rheumatol 17:462-466

7. Gennari L, Merlotti D, Valleggi F, Martini G, Nuti R (2007) Selective estrogen receptor modulators for postmenopausal osteoporosis: current state of development. Drugs Aging 24:361-379

8. Roux C, Fechtenbaum J, Kolta S, Isaia G, Andia JB, Devogelaer JP (2008) Strontium ranelate reduces the risk of vertebral fracture in young postmenopausal women with severe osteoporosis. Ann Rheum Dis 67:1736-1738

9. Blick SK, Dhillon S, Keam SJ (2008) Teriparatide: a review of its use in osteoporosis. Drugs 68:2709-2737

10. Cramer JA, Gold DT, Silverman SL, Lewiecki EM (2007) A systematic review of persistence and compliance with bisphosphonates for osteoporosis. Osteoporos Int 18:1023-1031

11. Kothawala P, Badamgarav E, Ryu S, Miller RM, Halbert RJ (2007) Systematic review and meta-analysis of real-world adherence to drug therapy for osteoporosis. Mayo Clin Proc 82:1493-1501

12. Gold DT, Silverman S (2006) Review of adherence to medications for the treatment of osteoporosis. Curr Osteoporos Rep 4:21-27
13. Adachi J, Lynch N, Middelhoven H, Hunjan M, Cowell W (2007) The association between compliance and persistence with bisphosphonate therapy and fracture risk: a review. BMC Musculoskelet Disord 8:97

14. Imaz I, Zegarra P, González-Enríquez J, Rubio B, Alcazar R, Amate JM (2009) Poor bisphosphonate adherence for treatment of osteoporosis increases fracture risk: systematic review and metaanalysis. Osteoporos Int. E-pub 9th December 2009

15. Penning-van Beest FJ, Erkens JA, Olson M, Herings RM (2008) Loss of treatment benefit due to low compliance with bisphosphonate therapy. Osteoporos Int 19:511-517

16. Penning-van Beest FJ, Goettsch WG, Erkens JA, Herings RM (2006) Determinants of persistence with bisphosphonates: a study in women with postmenopausal osteoporosis. Clin Ther 28:236-242

17. Kertes J, Dushenat M, Vesterman JL, Lemberger J, Bregman J, Friedman N (2008) Factors contributing to compliance with osteoporosis medication. Isr Med Assoc J 10:207-213

18. Lekkerkerker F, Kanis JA, Alsayed N, Bouvenot G, Burlet N, Cahall D, Chines A, Delmas P, Dreiser RL, Ethgen D, Hughes N, Kaufman JM, Korte S, Kreutz G, Laslop A, Mitlak B, Rabenda V, Rizzoli R, Santora A, Schimmer R, Tsouderos Y, Viethel P, Reginster JY (2007) Adherence to treatment of osteoporosis: a need for study. Osteoporos Int 18:1311-1317

19. Cramer JA, Roy A, Burrell A, Fairchild CJ, Fuldeore MJ, Ollendorf DA, Wong PK (2008) Medication compliance and persistence: terminology and definitions. Value Health 11:44-47

20. Steiner JF, Prochazka AV (1997) The assessment of refill compliance using pharmacy records: methods, validity, and applications. J Clin Epidemiol 50:105-116

21. Morisky DE, Green LW, Levine DM (1986) Concurrent and predictive validity of a self-reported measure of medication adherence. Med Care 24:67-74

22. Thompson K, Kulkarni J, Sergejew AA (2000) Reliability and validity of a new Medication Adherence Rating Scale (MARS) for the psychoses. Schizophr Res 42:241-247

23. Kripalani S, Risser J, Gatti ME, Jacobson TA (2009) Development and evaluation of the Adherence to Refills and Medications Scale (ARMS) among low-literacy patients with chronic disease. Value Health 12:118-123

24. Hahn SR, Park J, Skinner EP, Yu-Isenberg KS, Weaver MB, Crawford B, Flowers PW (2008) Development of the ASK20 adherence barrier survey. Curr Med Res Opin 24:21272138

25. Girerd X, Hanon O, Anagnostopoulos K, Ciupek C, Mourad JJ, Consoli S (2001) Assessment of antihypertensive compliance using a self-administered questionnaire: development and use in a hypertension clinic. Presse Méd 30:1044-1048

26. Bouée S, Charlemagne A, Fagnani F, Le Jeunne P, Sermet C, Naudin F, Lancry PJ (2004) Changes in osteoarthritis management by general practitioners in the COX2-inhibitor era-concomitant gastroprotective therapy. Joint Bone Spine 71:214-220

27. Cramer JA, Lynch NO, Gaudin AF, Walker M, Cowell W (2006) The effect of dosing frequency on compliance and persistence with bisphosphonate therapy in postmenopausal women: a comparison of studies in the United States, the United Kingdom, and France. Clin Ther 28:1686-1694

28. Cotté FE, Fardellone P, Mercier F, Gaudin AF, Roux C (2010) Adherence to monthly and weekly oral bisphosphonates in women with osteoporosis. Osteoporos Int 21:145-155

29. Crochard A, El Hasnaoui A, Pouchain D, Huas D, Arnulf I, Krieger J, Lainey E, Le Jeunne P, Léger D, Schuck S, Texier N, Tison F, Montplaisir J (2007) Diagnostic indicators of restless legs syndrome in primary care consultations: the DESYR study. Mov Disord 22:791-797

30. Chassany O, Le-Jeunne P, Duracinsky M, Schwalm MS, Mathieu M (2006) Discrepancies between patient-reported outcomes and 
clinician-reported outcomes in chronic venous disease, irritable bowel syndrome, and peripheral arterial occlusive disease. Value Health 9:39-46

31. Van Ganse E, Laforest L, Alemao E, Davies G, Gutkin S, Yin D (2005) Lipid-modifying therapy and attainment of cholesterol goals in Europe: the Return on Expenditure Achieved for Lipid Therapy (REALITY) study. Curr Med Res Opin 21:1389-1399

32. Fagnani F, German-Fattal M (2003) Antibiotic prescribing patterns of French GPs for upper respiratory tract infections: impact of fusafungine on rates of prescription of systemic antibiotics. Am J Respir Med 2:491-498

33. Bagneux V, Barnes N, Arnould B (2007) Development of a standardized face and content validity test to evaluate patient questionnaires for clinical practice. PRO Newsl 38:12-14

34. Caro JJ, Ishak KJ, Huybrechts KF, Raggio G, Naujoks C (2004) The impact of compliance with osteoporosis therapy on fracture rates in actual practice. Osteoporos Int 15:1003-1008

35. Cotté FE, Mercier F, De Pouvourville G (2008) Relationship between compliance and persistence with osteoporosis medications and fracture risk in primary health care in France: a retrospective case-control analysis. Clin Ther 30:2410-2422

36. Huas D, Debiais F, Blotman F, Cortet B, Mercier F, Rousseaux C, Berger V, Gaudin AF, Cotté FE (2010) Compliance and treatment satisfaction of post menopausal women treated for osteoporosis. BMC Womens Health 10:26

37. Garber MC, Nau DP, Erickson SR, Aikens JE, Lawrence JB (2004) The concordance of self-report with other measures of medication adherence: a summary of the literature. Med Care 42:649-652

38. Nau DP, Steinke DT, Williams LK, Austin R, Lafata JE, Divine G, Pladevall M (2007) Adherence analysis using visual analog scale versus claims-based estimation. Ann Pharmacother 41:1792-1797
39. Reinhard MJ, Hinkin CH, Barclay TR, Levine AJ, Marion S, Castellon SA, Longshore D, Newton T, Durvasula RS, Lam MN, Myers H (2007) Discrepancies between self-report and objective measures for stimulant drug use in HIV: cognitive, medication adherence and psychological correlates. Addict Behav 32:27272736

40. Jentzsch NS, Camargos PA, Colosimo EA, Bousquet J (2009) Monitoring adherence to beclomethasone in asthmatic children and adolescents through four different methods. Allergy 64:14581462

41. van de Steeg N, Sielk M, Pentzek M, Bakx C, Altiner A (2009) Drug-adherence questionnaires not valid for patients taking bloodpressure-lowering drugs in a primary health care setting. J Eval Clin Pract 15:468-472

42. Chisholm MA, Lance CE, Williamson GM, Mulloy LL (2005) Development and validation of the immunosuppressant therapy adherence instrument (ITAS). Patient Educ Couns 59:13-20

43. de Klerk E, van der Heijde D, van der Tempel H, van der Linden S (1999) Development of a questionnaire to investigate patient compliance with antirheumatic drug therapy. J Rheumatol 26:2635-2641

44. Vandekerckhove M, Vermeire E, Weeren A, Van Royen P (2009) Validation of the Diabetes Obstacles Questionnaire (DOQ) to assess obstacles in living with type 2 diabetes in a Belgian population. Prim Care Diab 3:43-47

45. Lau E, Papaioannou A, Dolovich L, Adachi J, Sawka AM, Burns S, Nair K, Pathak A (2008) Patients' adherence to osteoporosis therapy: exploring the perceptions of postmenopausal women. Can Fam Physician 54:394-402

46. Foddy W (1993) Constructing questions for interviews and questionnaires: theory and practice in social research. Cambridge University Press, Cambridge 